\title{
The lived experience of people newly diagnosed with dementia: A narrative study using a phenomenological approach
}

\author{
Suzanne Holland ${ }^{1}$, Angela Kydd ${ }^{2}$ \\ 1. NHS Ayrshire and Arran Mental Health Services, U.K. 2. Institute of Older People's Health and Well-being, University of \\ the West of Scotland, U.K.
}

Correspondence: Suzanne Holland. Address: School of Health Nursing and Midwifery, Ayr Capmus, University of the West of Scotland, U.K. Email: suzanne.holland@uws.ac.uk

Received: October 9, 2013

Accepted: November 28, 2013

Online Published: December 22, 2013

DOI : $10.5430 /$ cns.v2n1p80

URL: http://dx.doi.org/10.5430/cns.v2n1p80

\section{Abstract}

Aim: This qualitative study was undertaken to explore the lived experience of people newly diagnosed with dementia at one local post-diagnostic counselling service in Scotland.

Methods: A interpretative phenomenological approach was adopted, data was collected by means of one-to one interviews with people newly diagnosed with dementia.The process of ethical approval was lengthy and conditions attached to recruitment. Of 9 possible participants, 3 women were recruited. Due to the small number, results were presented as individual narratives.

Results: The 3 women all reported a long wait for the service following diagnosis and they were unclear as to the purpose of the service. All reported a reluctance to attend the counselling service.Two women had family support and found talking to the nurse counseellor very helpful.One woman had no such support and perceived the service to be a covert form of further assessment.

Conclusions: Although positive steps have been taken towards improving the service, the uptake was poor. One of three participants perceived this service to be another form of assessment, which shows the heightened anxiety of people newly diagnosed with dementia. This is especially so for people with no supportive friends and/or family.

Recommendations: From this small study it appears that post diagnostic counselling needs to be offered at time of diagnosis. It also appears that careful attention should be given to all forms of communication with people newly diagnosed with dementia, as they are at a vulnerable time in their lives and are frightened by service interventions.

\section{Key words}

Dementia, Diagnosis, Counselling, Qualitiative research

\section{Introduction}

In the United Kingdom (UK), the fundamental role of early diagnosis, treatment and support of people with dementia has become well recognised ${ }^{[1,2]}$. Advances in pharmacological treatments have led to the right of people with dementia to have a timely diagnosis, being identified as a priority within Scotland's National Dementia Strategy ${ }^{[3]}$, The National 
Dementia Action Plan for Wales ${ }^{[4]}$ and Northern Ireland's draft dementia strategy ${ }^{[5]}$. Diagnostic disclosure in dementia is also receiving worldwide support ${ }^{[6,7]}$. Evidence based practice recommends that post diagnostic counselling be implemented as a fundamental part of the process of diagnostic disclosure in dementia care ${ }^{[8-10]}$. However, much of the research in this area of practice has omitted to include the perspective of the person with dementia, despite the fact that these people will be the best source of legitimate data. The aim of this study was to explore the experience of people newly diagnosed with dementia who attended a post-diagnostic counselling service within the West of Scotland.

\section{Aim}

This qualitative study explored the lived experience of people newly diagnosed with dementia at one local post-diagnostic counselling service in Scotland.

\section{Methods}

This qualitative study used an interpretative phenomenological approach. Phenomenology focuses on increasing the understanding of the perspective of the lived experience of research participants and can serve to assist nurses to campaign for effective services ${ }^{[11]}$. The philosophical ideas of Heidegger and Husserl underpin the phenomenological approach to enquiry ${ }^{[12]}$ which can be either descriptive or interpretive. Husserl is associated with the descriptive phenomenologist approach which seeks to describe human experience whereas Heidegger is linked with interpretive phenomenology which aspires not only to describe, but to analyse and understand ${ }^{[13]}$. A further differentiating factor in descriptive and interpretive phenomenology, relating to the management of researcher bias, is that the descriptive phenomenological approach endeavours to take a scientific approach to enquiry and holds the view point that any personal values must be set aside in order that the researcher may approach the area of study with objectivity ${ }^{[14]}$. However, interpretive phenomenologists believe that it is not possible to set personal experiences and values aside as they form an intrinsic part of the research process ${ }^{[15]}$. According to Flood ${ }^{[16]}$, the presuppositions of the researcher can help understanding of the experiences of research participants to be developed. Silverman ${ }^{[17]}$, states that it is the personal values and experiences which researchers bring to the research process which enable problems to be identified and studied.

\subsection{Recruitment of participants}

The sample was purposeful. Participants were recruited from the lead author's last place of employment; a community mental health team which runs a post diagnostic clinic for people newly diagnosed with dementia. Only people who were deemed medically able to consent, had a score of 18 or above on the Mini Mental State Examination (MMSE), were able to communicate in English and had received post diagnostic counselling at the clinic were recruited to the study. A total of 9 people were issued with appointments for the post-diagnostic service during the 4 month study period, but only 6 attended. Four people agreed to take part in the study, but the consultant psychiatrist suggested 1 person was not a suitable participant and therefore 3 people in total participated in this study.

\subsection{Data collection}

The lead author, who is an experienced nurse in dementia care, conducted one-to-one, semi-structured, audio-taped interviews in keeping with an interpretative phenomenological approach ${ }^{[18,19]}$. Consideration was given to the use of focus groups as a means of data collection. However, Hinton ${ }^{[20]}$ highlights concern that the focus group setting may not be helpful for the discussion of sensitive and potentially stigmatising issues. Bryden ${ }^{[21]}$ also reports concern that people with dementia may find it very difficult to share their feelings with regard to their diagnosis in a group setting.

One-to-one, audio-taped interview was therefore chosen as the method of data collection. This ensured that the researcher was able to give the research participant her undivided attention, thus allowing the responses and reactions of the people with dementia and their significant others (when applicable) to be captured and systematically analysed at a later date. Interviews were conducted in a semi-structured manner in keeping with the phenomenological approach ${ }^{[19]}$. As a means of 
maximising potential for recall, interviews were carried out within 1 week post counselling. An opening statement set the course of the interview and an additional set of questions were devised to prompt discussion, if required (see below). This method of data collection allows the creation of a relationship which enables both researcher and participant to actively take part in the research process and "tell it in their own words" ${ }^{[22,23]}$. Furthermore, Parahoo ${ }^{[18]}$ also acknowledges that one-to-one interviewing enables a close up view of the area of study to be obtained.

\subsection{Analysis}

The interviews were transcribed and as there were only three participants, the results were recorded as invidividual narratives.The narrative approach can be used as a means of portraying and preserving the perspectives of vulnerable clients in an ethical and non-intimidating manner ${ }^{[24]}$. It is a phenomenological approach, concerned with capturing research participants expressed views and understanding of lived experiences ${ }^{[25,26]}$. Within narrative analysis, the lived experience of research participants is related in narrative format ${ }^{[27]}$.

Each narrative was long and informative and was repeatedly read and re-read and manually analysed. This produced valuable insight into the lived experience of receiving a diagnosis of dementia and the meaning of post-diagnostic counselling from the perspective of the 3 women who took part in this study and similarities and disparities to be identified $^{[28]}$.

During the process of analysis, extracts were selected to address the following research questions:

- What is the value of post-diagnostic counselling from the perspective of the person with dementia?

- Is the nurse counselling service meeting the post-diagnostic needs of people with dementia?

- Is the post-diagnostic clinic demonstrating best practice in this area of care?

\subsection{Data collection tool}

The semi structured interview posed the following open-ended questions:

- May I ask what you and the nurse spoke about when you met?

- Can you tell me what if felt like to speak with the nurse about your condition?

- Can you tell me, what in your opinion were the positive and/or negative experiences of speaking with the nurse?

- Can you tell me what, if anything would have made the meeting with the nurse more worthwhile for you?

\subsection{Procedures}

Psychological support for participants must be in place in such studies ${ }^{[17]}$. The lead author had experience in this field and was able to act in a supportive role to people who are attempting to adjust to their diagnosis ${ }^{[29]}$. An additional consideration was the choice of interview setting to keep stress to a minimum and foster a good researcher / participant relationship ${ }^{[21,30]}$. Each participant chose to be interviewed at home rather than at the clinic. Time was afforded to each participant to speak at their leisure during interview ${ }^{[31]}$ and paraphrasing and supportive comments were used to help participants to remember the content of the discussion and to recognise the value of their views ${ }^{\text {[32] }}$.

\subsection{Confidentiality}

Participants were all assured that confidentiality would be respected at all times. All information obtained has remained strictly confidential and was stored by the researcher in line with the principles of the NHS Code of Practice on Protecting Patient Confidentiality ${ }^{[33]}$. Each participant was given identification numbers upon commencement of the study in order to ensure the protection of their privacy ${ }^{[34]}$. The key for the identification numbers was kept completely separate from the 
data throughout the course of this study in order to ensure confidentiality was maintained. Pseudonyms were used to report the narratives in the results.

\subsection{Ethical approval}

Gaining ethical approval was a major component of this study due to the vulnerable nature of the participants and the fact that the research was being conducted at a time when the participant had recently received a devastating diagnosis. Whilst all studies researching participants views are subject to rigorous scrutiny by ethics boards, participants who are cognitively impaired and/or who are undergoing a stressful life event need extra consideration.

People with dementia are often perceived being "difficult to reach" within the world of research in part due to the presence of their cognitive impairment and also as a result of the scrutiny of research involving people with dementia by ethics committees ${ }^{[31,35]}$. The researcher did give careful consideration to the design of the study and steps were taken to ensure that ethical issues arising from the study were addressed. The researcher was required to evidence the process of ensuring valid informed consent and ethical recruitment to three separate research ethics review boards and hierarchical members of the individual research participants direct care team before ethical approval for the conduct of the study was gained. Ethical approval for the study was gained from the University of the West of Scotland ethics committee, NHS Ayrshire and Arran Research and Development Department. Ethical aproval was also recevied from the West of Scotland Research Ethics Committee (WoRSEC) following confirmation of agreed compliance with the following conditions:

- Condition 1: The obtainment of managerial permission to conduct the research from the host organisation.

- Condition 2: Confirmation of capacity of the client would be obtained from the Consultant Psychiatrist before the researcher approached the client.

- Condition 3: Local lone working proceedures would be followed for home visits.

\section{Results}

The 3 participants were white females living in Scotland and for the purpose of ensuring anonymity each have been given pseudonyms of Jane, Julie and Bertha.

Jane was 77, Julie was 70 and Bertha was 81 years old. Jane and Bertha were both married. Jane had 3 sons and Bertha had 1 daughter. Julie had 2 sons, but was widowed.

Each woman had received a diagnosis of Alzheimer's disease and each had a Mini Mental State Examination score above 20, indicating mild cognitive impairment.

The findings are presented as individual cases in a narrative format.This phenomenological approach portrays the perspectives of vulnerable clients ${ }^{[24]}$, presents the expressed views of the lived experiences of individuals ${ }^{[25,26]}$ in narrative format ${ }^{[27]}$ and allows for similarities and disparities to be identified ${ }^{[28,36]}$.

Extracts from the narratives from each of the three women are presented in this paper in order to illustrate the impact of a diagnosis of dementia and the experience of nurse counselling.

\subsection{Jane's story}

Jane had her husband present for the interview. She said that she had been attending a local memory clinic (with her husband) for just over a year prior to diagnosis. However, as a result of little professional support between clinic appointments, which can often be several months apart, Jane had felt neglected. Even her referral to the post-diagnostic service had taken a few weeks. She said, “I just felt that they weren’t bothering, that's what I felt”. 
Although Jane had expressed a wish to be informed of her diagnosis, she was shocked when she received the news. "Well I didn't believe him [the consultant psychiatrist]...I thought he was telling me a lot of piffle”. She expressed her dislike of the consultant psychiatrist who gave her the diagnosis, saying "I didn't want to see him again...I didn't like his attitude at all”. Jane also expressed concern regards the stigma of her diagnosis and confided “I haven’t told anybody, I haven’t told any of my family or anything. At this point her husband reassured her that the family knew.

Jane had no recall of her conversation with the nurse counsellor about her feelings related to her dementia diagnosis. She reported "I cannot remember I was in such a state". Nevertheless, she did remember how she felt about her contact with her nurse counselor "Oh she was awful nice, really awful nice... such a lovely person...she was brilliant...explained everything to me”. Jane received educational materials from the nurse counsellor during the session and these did raise questions for Jane about the future impact of her diagnosis. She reported that she felt "where is it going to go? How far is it going to go? How long is it going to take to get there?” These thoughts distressed her. However, on further questioning Jane said she did get some benefit from the information, but this could have been because she wanted to appear positive because she said "Oh it made me feel a bit better, [the information] but then I just wondered where it was going to end". Jane became tearful during the interview stating "some days I just feel down". However, she spoke of her family, stating "my great granddaughter, that's what brings happiness”.

Jane did not think that there was anything that could have made the counselling meeting more valuable because the nurse was "very, very good". She felt reassured when informed she could contact he the nurse counsellor again in the future if she so wished. Although she said "I felt better after that", she also indicated that she had no intention of contacting any services.

\subsection{Julie's story}

Julie lived alone in the marital home that she and her husband had once shared. She had no close friends in whom she could confide. Her 2 sons lived nearby and were supportive, but both worked long hours. Julie was aware of her diagnosis, but said "I really don't want to dwell on it you know, to me if I dwell on it all the time, it would be a depression. I have absolutely no desire to be sad or worried or anything like that; I just want to get on with things".

During the interview, Julie repeatedly expressed fears regards loss of autonomy and the threat of institutionalisation associated with her diagnosis of dementia. She reported "I don't want to accept that someone could actually put me away, because that would kill me”. She admitted that her diagnosis had led to a lack of trust in mental health professionals, stating that "as long as they are labelling me I feel under threat...To me it is like a prison sentence. Like one day they are going to take me away". Julie was fearful and suspicious of services; she said that she felt any information given to professionals would at some time in the future be "used as ammunition against her". She stated that she had been reluctant to participate in counselling as she thought it was just another way to test her abilities, she was very frightened. Julie said that attendance at the counselling service was an anxious time, she was“not happy, on edge, as it really wouldn't matter what I say, any of these officials, if they decide that I should be taken into a home or something like that, there isn't anything I can do about it, I would just be yanked out, now that is the thing that scares the life out of me”. She also stated that she felt threatened by her attendance at the counselling service and reported "I was on my guard". Julie was also able to recall "the nerves of going” to her counselling appointment. She went on to say “ I wouldn't like to make it a regular thing, because that is a reminder about what other people think of you" She said "I was just glad the meeting was over and done with and I was coming home...Listen, I could have run along the street as fast as I could go”.

\subsection{Bertha's story}

Bertha lived at home with her husband and her daughter Vera, who acted as the couple's main carer. Vera was present during the interview at Bertha's request. Receiving a diagnosis of dementia had been a shock for Bertha. She reported "I couldn't believe that, I was a bit upset you know but it didn’t last long, I thought it must be right so I accepted it”. Bertha said she had not been too distressed following diagnosis. She had a very positive view of the support which she had 
received from the consultant psychiatrist when he gave her her diagnosis. She said he was "very calm and easy to talk to, very, very nice”. Her daughter Vera praised the consultant's sensitive and caring manner, but said that that she and her mother had received inadequate information about the counselling service prior to attendance. She stated "I wasn't particularly sure why we were going to that meeting. I knew we were going to see the nurse counsellor but I didn’t know what her role was". Vera also indicated that the waiting time for her mother to be seen at the nurse counselling service was "maybe a little longer than perhaps we might have liked" but she did say she was "pleasantly surprised that the nurse counsellor was able to give us so much information which was great”. However she also said that she was expecting to talk "more about the personal side of mum's condition".

Bertha was able to recall her meeting with her nurse counsellor and reported "I was a wee bit nervous, but she was very kind and calm and I found that helpful". She said that she could "get angry" if asked to speak about her dementia, but these feelings were more about her frustration and unease; Vera explained that the stigma associated with dementia was extremely frightening “especially for someone of mum's generation”. However, Bertha reported that her nurse counsellor "was a very nice person, very easy to talk to and I sat and listened to her, I enjoyed her company, it wasn't hard to talk to her".

Bertha was pleased to have met the nurse counsellor, reporting, "she was a very nice person, she was more used to talking to people like me...She was easy to talk to and it just sort of flowed along if you like". She also said that she would welcome the opportunity to meet with the nurse counsellor again, stating "yes, anything that helps your feelings". She disclosed that "I have been just a little worried but just at the beginning, just thinking about things, no it's fine, I have come to accept it”. Bertha stated "I've got a nice family and that is all I need".

\section{Discussion}

This study utilised narratives to explore the meaning of the experience of nurse counselling from the perspective of the person newly diagnosed with dementia. It was interesting that 2 of the women had family members present at their request, supporting findings ${ }^{[11,21]}$ in the literature regarding the importance of the family to many people with dementia. Confirmation of a diagnosis of dementia was initially perceived by all 3 women as being a devastating concept to consider. The findings of this study would therefore parallel the findings of studies ${ }^{[37,38]}$ that people with dementia are often unaware of their condition, pre-diagnosis.The news of a diagnosis of dementia was met with feelings of shock and disbelief and was upsetting for all three women. This study therefore supports previous findings ${ }^{[39-41]}$ with regard to a diagnosis of dementia causing emotional distress.

However, the significance of the sense of feelings of loss and distress experienced did vary between the women in relation to the level of support which they did/did not have. The disclosure of a diagnosis of dementia appeared to cause a short term period of emotional upset for 1 woman, Bertha. However, there was an association with the development of depressive symptoms for the other 2 participants, Jane and Julie. Narratives obtained during the course of this study therefore support previous reports regards the common connection between depressive symptoms and a diagnosis of dementia ${ }^{[42,43]}$.

Fears associated to the stigma of dementia did result in reluctance from people to engage in open discussion about their condition, which mirrors other studies ${ }^{[41]}$. This was certainly the case with Julie, who felt very much alone and was scared of the services taking over her life. The level of fear associated to feelings of loss of control and the preservation of self was undoubtedly greatest for Julie, who lived on her own. The stress of Julie's struggle to retain a balance between acknowledging feelings of loss and preservation of autonomy was clearly depicted by her narrative. However, it did appear that family members also tried to protect the person with dementia through the avoidance of open discussion about their diagnosis. Feelings of fear commonly associated to the "label" of dementia were reported, findings supported by several recent studies ${ }^{[44-46]}$. 
The diagnosis of dementia did also result in Jane and Julie feeling hostile towards the professional staff involved in the disclosure process. This could have been due to the women's own feelings or it could have been due to a poor attitude from professional staff. Sadly this did adversely affect the development of a trusting relationship which is vital to supporting their post-diagnostic needs. This finding echo a study by Steenman ${ }^{[47]}$ who found that fears associated with the stigma of dementia can be a factor in the inability of nursing and medical staff to provide empathy and support during the process of diagnostic disclosure. It also endorses the findings of studies emphasizing the need for professionals to be clear, considerate and compassionate when informing someone that they have a diagnosis of dementia ${ }^{[48,49]}$.

It is evident from the narratives that none of the women had clear recall of discussions undertaken during the process of diagnostic disclosure. However, all remained in touch with their emotions and were clearly able to recall how they felt during their contact with the consultant psychiatrist and during their meeting with the nurse counsellor. However, each person had a different perspective with regards to their experience of both the disclosure process and the post-diagnostic counselling.

The narratives obtained during the course of this study highlight that Jane and Bertha did experience feelings of comfort, support and reassurance post-diagnosis from the counsellor. This would endorse the previous findings of studies about the potential valuable role of nurses in post diagnostic care ${ }^{[47,50]}$. However, the nurse counsellor had perhaps not known how alone Julie felt. Julie was terrified and stressed before and during her counselling appointment because it was her perception that the meeting was being used as a means of subjecting her to further assessment, failure would result in her greatest fear of institutionalisation being realised. It was also stated by Bertha's daughter that the service seemed more about giving information rather than counselling.

It was interesting that Julie agreed to be interviewed for this study, given that she initially thought it was yet another test. This perception may be shared by many and it is noteworthy that 3 people with dementia, either cancelled or did not attend their counselling appointment during this study period. It could mean that those who did not attend were either frightened that the counselling offered was just another way to assess them. It therefore could be argued that like Julie, some people with dementia may actually wish support but are fearful of the implications of giving information to professional services, or it could add weight to a report from the Royal College of Psychiatrists ${ }^{[51]}$ that not everyone may want or benefit from the provision of counselling.

Lengthy gaps in professional support and inadequate information during the diagnostic care pathway were also highlighted. This was found to have the potential to negatively impact on the doctor/patient relationship; result in confusion regards the care process and lead to the development of feelings of abandonment/increased distress. The results of this study therefore also support the findings of the National Audit Office Report ${ }^{[52]}$, the Scottish Government ${ }^{[53]}$ and the Department of Health Social Services and Public Safety ${ }^{[5]}$ that people with dementia and their significant others do not always receive the correct amount of information or adequate support post diagnosis.

\section{Conclusion}

The study did not address the nature of the service, but the uptake to the service by people with dementia and then their experiences of the service.

It has found that, whilst positive steps have been taken towards improving the post-diagnostic care of people newly diagnosed with dementia, the timing of the service following diagnosis is not ideal. The two women who found attendance at the post-diagnostic service helpful had additional family member support but the one woman who did not, experienced additional stress from this service because she felt that she was undergoing a further form of assessment following her diagnosis of dementia. She did not find counselling helpful and in contrast, perceived it as being a further threat to autonomy. The concept of the service was questioned by Bertha's daughter in that it appeared to be more about giving 
information than talking about feelings. However, should the counselling be offered and given immediately after diagnosis (as it is with breast cancer for example) then people newly diagnosed with dementia would not see this as a further appointment to be made to emphasise that this person now has dementia.

This study also highlighted a poor up-take of counselling during the study period, with one third of clients not attending their allocated counselling appointment. The reason for this remains unknown. However, fears associated to the stigma of a diagnosis of dementia, or fears that counselling is another form of covert assessment may be a contributing factor in low rates of at attendance at the counselling service.

This small study points to the need for larger research studies in order to hear from individuals what needs they have following diagnosis of dementia.

\section{References}

[1] Department of Health. Research Governance Framework for Health and Social Care 2nd edition. London: Department of Health; 2006.

[2] Department of Health. Living Well with Dementia: The National Dementia Strategy.London: Department of Health; 2009.

[3] Scottish Government. Scotland's National Dementia Strategy. The Scottish Government: Edinburgh; 2010.

[4] Welsh Assembly Government. The National Dementia Action Plan for Wales.Welsh Assembly Government: Cardiff; 2009.

[5] Department of Health, Social Services and Public Safety. Improving Dementia Services in Northern Ireland-Regional Strategy. Belfast: Department of Health, Social Services and Public Safety; 2010.

[6] Alzheimer Europe. Annual Report [Internet]. 2009 [cited 2013 Jan 30]; Available from: http//www.alzheimer-europe.org

[7] Alzheimer Disease International. World Alzheimer Report: The global economic impact of dementia. Alzheimer Disease International: London; 2010.

[8] Fearnley K, McLennan J, Weaks D. The Right to Know: Sharing the Diagnosis of Dementia. Alzheimer Scotland-Action on Dementia: Edinburgh; 1997.

[9] NHS Education for Scotland. An educational resource to support early interventions for people receiving a diagnosis of dementia. NHS Education for Scotland: Edinburgh; 2008.

[10] Eccles MP, Francis J, Foy R, Johnston M, Bamford C, Grimshaw JM, Hughes J, Lecouturier J, Steen N, Whitty PM. Improving professional practice in the disclosure of dementia: A modelling experiment to evaluate a theory based intervention. International Journal of Behavioural Medicine. 2009; Vol 16, 377-387. PMid:19424811 http://dx.doi.org/10.1007/s12529-008-9023-3

[11] De Witt L, Ploeg J, Black M. Living alone with dementia: an interpretive phenomenological study with older women. Journal of Advanced Nursing. 2010; 66 (8): 1698-1707. PMid:20557395 http://dx.doi.org/10.1111/j.1365-2648.2010.05295.x

[12] Gelling, J. What is the difference between grounded theory and phenomenology. Nursing Times. $2010 ; 107$ (4): 25.

[13] Polit, DF, and Beck, CT. Nursing Research Appraising Evidence for Nursing Practice $7^{\text {th }}$ ed., London: Wolters Kluwer/Lippincott Williams \& Wilkins; 2006.

[14] Balls, P. Phenomenology in nursing research: Methodology, interviewing and transcribing. Nursing Times. 2009; $105: 32-33$.

[15] Connelly, LM. What is phenomenology. MEDSURG Nursing. 2010; 19(2): 127-128. PMid:20476524

[16] Flood, A. Understanding phenomenology. Nurse Researcher. 2010; 17(2): 7-15. PMid:20222274 http://dx.doi.org/10.7748/nr2010.01.17.2.7.c7457

[17] Silverman, D. Doing Qualitative Research 2nd edition. Edinburgh: SAGE Publications Ltd; 2005. PMid:20222274

[18] Parahoo K. Nursing Research: Principles, Process and Issues 2nd Edition, London: Palgrave McMillan; 2006.

[19] Ryan F, Coughlan M, Cronin P. Step-by-step guide to critiquing research. Part 2: qualitative research. British Journal of Nursing. 2007; 16(12): 738-744. PMid:17851363

[20] Hinton, L. Qualitative research on geriatric mental health: progress, challenges and opportunities. American Journal Geriatric Psychiatry. 2010; 18(7): 563-566. PMid:20593534 http://dx.doi.org/10.1097/JGP.0b013e3181e16a26

[21] Bryden C. A person-centred approach to counselling, psychotherapy and rehabilitation of people diagnosed with dementia in the early stages. Dementia. 2009; 1(2): 141-156. http://dx.doi.org/10.1177/147130120200100203

[22] Jack B. Giving them a voice: the value of qualitative research. Nurse Researcher. 2010; 17(3): 4-6. PMid:20450083 http://dx.doi.org/10.7748/nr2010.04.17.3.4.c7740

[23] Shauver MJ, Chung KC. A guide to qualitative research in plastic surgery. Plastic and Reconstructive Surgery. 2010; 126(3): 1089-1097. PMid:20463619 http://dx.doi.org/10.1097/PRS.0b013e3181e60624

Published by Sciedu Press 
[24] Booth T, Booth W. Sounds of Silence: narrative research with inarticulate subjects. Disability Society. 1996; 11(1): 55-69. http://dx.doi.org/10.1080/09687599650023326

[25] Brown J, Dodd K, Vetere A. 'I am a normal man: a narrative analysis of the accounts of older people with Down’s syndrome who lived in institutionalised settings. British Journal of Learning Disabilities. 2009; 38(3): 217-224. http://dx.doi.org/10.1111/j.1468-3156.2009.00596.x

[26] Polkinghorne D.E. Narrative configuration in qualitative analysis. International Journal of Qualitative Studies in Education. 2006; 8(1): 5-23. http://dx.doi.org/10.1080/0951839950080103

[27] Redwood, R. Narrative and narrative analysis. Journal of Clinical Nursing. 1999; 8(6): 663-674. http://dx.doi.org/10.1080/0951839950080103

[28] Mello RA. Collocation analysis: a method for conceptualizing and understanding narrative data. Qualitative Research. 2002; 2(2): 231-243. http://dx.doi.org/10.1177/146879410200200206

[29] Gilmour JA, Huntington AD. Finding the balance: living with memory loss. International Journal of Nursing Practice. 2005; 11(3): 118-124. PMid:15853790 http://dx.doi.org/10.1111/j.1440-172X.2005.00511.x

[30] McKillop J, Wilkinson H. Make it easy on yourself! Advice to authors from someone with dementia on being interviewed. Dementia. 2004; 3(2): 117-125. http://dx.doi.org/10.1177/1471301204042332

[31] McKeown J, Clarke A, Ingleton C, Repper J. Actively involving people with dementia in qualitative research. Journal of Clinical Nursing. 2010; 19(13-14): 1935-1943. PMid:20920020 http://dx.doi.org/10.1111/j.1365-2702.2009.03136.x

[32] Sorrensen L, Waldorff E, Waldemar G. Early counselling and support for patients with mild Alzheimer's disease and their caregivers: a qualitative study on outcome. Aging and Mental Health. 2008; 12(4): 444-450. PMid:18791891 http://dx.doi.org/10.1080/13607860802224342

[33] NHS Scotland. Code of Practice on Protecting Patient Confidentiality. Edinburgh: Scottish Executive; 2003.

[34] Edvardson D, Nordvall K. Lost in the present but confident of the past: experiences of being in psycho-geriatric unit as narrated by persons with dementia. Journal of Clinical Nursing. 2008; 17(4): 491-498.

[35] Wilkinson, H. Innovative methodologies-can we learn from including people with dementia from South Asian Communities? Research Policy and Planning. 2003; 21(2): 43-54.

[36] Thorne S. Data analysis in quantitative research. Evidenced Based Nursing. 2010; 3(3): 68-70. http://dx.doi.org/10.1136/ebn.3.3.68

[37] Clare L. Managing threats to self: awareness in early stage Alzheimer’s disease.Social Science and Medicine. 2003; Vol 57 (6), 1017-1029. http://dx.doi.org/10.1016/S0277-9536(02)00476-8

[38] Byszewski AM, Molnar FJ, Aminzadeh F, Eisner M, Gardezi F, Bassett R. Dementia diagnosis disclosure: A study of patient and caregiver perspectives. Alzheimer Disease Association Discord. 2007; 21: pp. 107-114. PMid:17545735 http://dx.doi.org/10.1097/WAD.0b013e318065c481

[39] Husband HJ. The psychosocial consequences of learning a diagnosis of dementia: three case examples. Aging \& Mental Health. 2009; 3(2): 179-183. http://dx.doi.org/10.1080/13607869956352

[40] Husband HJ. Diagnostic disclosure in dementia: an opportunity for intervention? International Journal of Geriatric Psychiatry. 2000; 15: 544-547. http://dx.doi.org/10.1002/1099-1166(200006)15:6<544::AID-GPS241>3.0.CO;2-8

[41] Pratt R, Wilkinson H. A psychosocial model of understanding the experience of receiving a diagnosis of dementia. Dementia. 2003; 2(2): pp. 181-199. http://dx.doi.org/10.1177/1471301203002002004

[42] Iliffe S, Manthorpe J, Eden A. Sooner or later? Issues in the early diagnosis of dementia in general practice: a qualitative study. Family Practice. 2003; 20(4): 376-381. PMid:12876106 http://dx.doi.org/10.1093/fampra/cmg407

[43] Alzheimer Society. Factsheet 444: Depression [Internet]. 2010[cited 2013 Jan]. Available from: http://alzheimers.org.uk

[44] Clare L. Developing awareness about awareness in early stage dementia. Dementia. 2002; 1(3): 295-312. http://dx.doi.org/10.1177/147130120200100303

[45] Shakelton B, Harrison K, Taylor C. Dementia 2: Early diagnosis and initial nursing care. Nursing Times. 2008; 104(7): $26-27$.

[46] Holle R, Grabel E, Ruckdaschel S, Wunder S, Mehlig H, Mark P, Pirk O, Butzlaff M, Kunz S, Lauterberg J. Dementia care initiative in primary practice-study protocol of a cluster randomised trial on dementia management in a general practice setting. BMC Health Services Research. 2009; 9(1): 1452-1472. PMid:19500383 http://dx.doi.org/10.1186/1472-6963-9-91

[47] Steenman E, Dierckx B, Godderis J, Grypdonck M. Early counselling and support for patients with mild Alzheimer’s disease and their caregivers: a qualitative study on outcome. Aging and Mental Health. 2006; 12: 444-450.

[48] Downs M. How to tell? Disclosing a diagnosis of dementia. The American Society on Aging. 1999; 13(3): 30-34.

[49] Dersken E, Vernooij-Dassen M, Scheltens P, Olde Rikkert M. A model for disclosure of the diagnosis of dementia. Dementia. 2006; 5: 462-466. http://dx.doi.org/10.1177/147130120600500313 
[50] Weaks D, Johansen R. Developing an enhanced role for community mental health nurses working with early diagnosis of dementia, Healthcare Improvement Scotland and NHS Scotland; 2008. PMid:18469863

[51] Royal College of Psychiarists. Counselling not helpful in the immediate aftermath of a disaster [Internet]. 2007[cited 2013 Jan 30] Available from: www. rcpsych.ac.uk

[52] National Audit Office Report. Improving services and support for people with dementia, The Stationary Office: London; 2007.

[53] Scottish Government. Charter of Rights for People with Dementia and their carers in Scotland, The Scottish Government, Edinburgh; 2009. 